\title{
What do humans feel with mistreated humans, animals, robots, and objects? Exploring the role of cognitive empathy
}

\author{
Alan D. A. Mattiassi ${ }^{1}$ (D) Mauro Sarrica ${ }^{2}$ (D) Filippo Cavallo Ma $^{4,6} \cdot$ Leopoldina Fortunati $^{3}$ (D)
}

Accepted: 21 April 2021 / Published online: 16 May 2021

(c) The Author(s) 2021

\begin{abstract}
The aim of this paper is to present a study in which we compare the degree of empathy that a convenience sample of university students expressed with humans, animals, robots and objects. The present study broadens the spectrum of elements eliciting empathy that has been previously explored while at the same time comparing different facets of empathy. Here we used video clips of mistreated humans, animals, robots, and objects to elicit empathic reactions and to measure attributed emotions. The use of such a broad spectrum of elements allowed us to infer the role of different features of the selected elements, specifically experience (how much the element is able to understand the events of the environment) and degree of anthropo-/zoomorphization. The results show that participants expressed empathy differently with the various social actors being mistreated. A comparison between the present results and previous results on vicarious feelings shows that congruence between self and other experience was not always held, and it was modulated by familiarity with robotic artefacts of daily usage.
\end{abstract}

Keywords Empathy $\cdot$ Mistreatement $\cdot$ Familiarity with robots $\cdot$ Perceived experience $\cdot$ Anthropomorphism $\cdot$ Zoomorphism

Filippo Cavallo

filippo.cavallo@unifi.it

Alan D. A. Mattiassi

alan.mattiassi@gmail.com

Mauro Sarrica

mauro.sarrica@uniroma1.it

Leopoldina Fortunati

leopoldina.fortunati@uniud.it

1 Department of Humanities and Cultural Heritage, University of Udine, Udine, Italy

2 Department of Communication and Social Research, Sapienza University of Rome, Rome, Italy

3 Department of Mathematics, Computer Science and Physics, University of Udine, Udine, Italy

4 The Biorobotics Institute, Scuola Superiore Sant'Anna, Pontedera, PI, Italy

5 Department of Industrial Engineering, University of Florence, Florence, Italy

6 Department of Excellence in Robotics \& AI, Scuola Superiore Sant'Anna, Pisa, Italy

\section{Introduction}

The developments of social robotics are about to bring a new typology of artefacts into people's everyday lives. Robots with a certain degree of autonomy will have the ability to interact with humans and with each other, to assist other agents in executing complex tasks, and the capacity to engage with humans on an emotional level through play and even companionship (Breazeal, 2003; Dautenhahn \& Billard, 1999; Shaw-Garlock 2011; Fiorini et al., 2017). In the expectations of many, sociable robots will be able to grasp interests, emotional states, and goals of humans (Fong, Nourbakhsh, \& Dautenhahn, 2003; Cavallo et al., 2014). They will be designed as socially intelligent in a humanlike way, and their social interfaces will include attributes by which an observer will judge them as social interaction partners (Breazeal, 2002; de Graaf, Ben Allouch, \& van Dijk, 2019; Hegel, Muhl, Wrede, Hielscher-Fastabend, \& Sagerer, 2009; Cavallo et al., 2018). Moreover, although these ideas often trigger images of human-like or animal-like machines, these expectations should be further extended (Barile \& Sugiyama, 2015; Fortunati, 2013, 2018) to other typologies of embodied technologies: "situated at the outer boundary of human and nonhuman interface" (Shaw-Garlock, 2009, 
p. 257). In the foreseen complex human-robot environment, psychological processes such as anthropomorphization, mind perception and emotional attachment, which have been examined in relation to objects, ICTs, and animals, seem to acquire a specific relevance when related to robots as human-like agents (Broadbent 2017). In particular, empathy will be an important competence and a crucial social skill (Riek, Rabinowitch, Chakrabarti, \& Robinson, 2009).

Current projects address empathy along two parallel lines. The internal approach aims to artificially reproduce animal and human emotional reactions, and so to develop relations based on similar forms of empathy. The external approach tests the possibility of increasing robots capacity to mimic human expressions. Such anthropomorphism adds an affective dimension to interactions, increases perceived empathy, and leads to greater social acceptance and positive and durable social interactions (Leite et al., 2013). Interactionist approaches link these two perspectives, and stress that empathic processes precisely connect the inner and the social, as its function is to regulate relations among actors (Damiano, Dumouchel, \& Lehman, 2015). Such a relational view is nicely expressed in the following citation: "When I attempt to understand the other person, I do not try to get inside their mind; I try to get inside their world-a world that I share with them" (Gallagher, 2007, p. 441; see also Tomasello, 2014).

A number of potential ethical concerns are however intertwined with empathic robots. On the one hand, concerns have been pointed out about the fact that a fake empathic relationship could affect empathy in dyadic encounters among humans (Misra, Cheng, Genevie, \& Yuan, 2016). On the other hand, these robots could be used to provide empathic nudges to their human companion and enhance their empathic abilities (Borenstein \& Arkin, 2017). Even if for positive goals, however, robots programmed to surreptitiously influence human behaviors not only evoke moral issues related to deception and manipulation (Sparrow \& Sparrow, 2006), but are also disturbing because they would deeply undermine the perceived uniqueness and superiority of animals and humans as moral agents (Turkle, 2010).

From a different angle, ethical concerns regard the abuses of social robots (e.g. Bartneck, Rosalia, \& Menges 2005; Brahnam \& De Angeli, 2008; Brščić, Kidokoro, Suehiro, \& Kanda, 2015). In particular, Darling suggests that abuse protection towards social robots should follow the analogy of animal abuse protection laws. In fact, by blurring the line between lifelike and alive, there is a risk that abusive behaviors towards lifelike objects will impact our capacity to feel empathy to the other living beings, including humans (Darling, 2016). Going beyond the animal analogy and the anthropocentric perspective, other authors have pointed out that the discursive and cultural meanings associated with new human-robots relationships may have as an outcome the recognition of the moral standing of robots (Coeckelbergh, 2018). Empirical studies support this vision and show that human bystanders who assist abusive behaviors towards robots are more prone to intervene in support, if robots showed more empathic behaviors towards humans in previous interactions and a passive acceptance of abuses (Tan, Vázquez, Carter, Morales, \& Steinfeld, 2018).

The importance of the present study lies on the fact that we contrasted three different types of robot: an anthropomorphic robot with a bipedal human structure, a zoomorphic robot and a machine-like robot with humans, animals and inanimate objects. By using different typologies of robots and comparing them with entities from other domains, this paper contributes to the study of empathy with robots outside the human-machine-like axis (Bartneck, Kanda, Ishiguro, \& Hagita, 2007; Ferrari, Paladino, \& Jetten, 2016; Löffler, Dörrenbächer, \& Hassenzahl, 2020; Mori, 1970; Seyama \& Nagayama, 2007). It presents an experiment in which we compare the degree of empathy elicited by a set of selected elements being mistreated by using as stimuli videos of participants belonging to different realms (humanity, animals, robots, and inanimate objects) that have so far been explored separately or combined in a different way.

In the next section, before presenting the study, we summarize some of the main issues of the debate regarding empathy, especially empathy toward animals and inanimate objects.

\section{Empathy}

Empathy is a fuzzy theoretical construct that has been employed to refer to related yet different processes (Stueber, 2017; Wispe, 1986). Used by classic Greek philosophers to identify the process that leads the public to identify in the actors, it is only in the eighteenth century (with Herder) and in the nineteenth century (with German aesthetes) that empathy began to acquire its current meaning (Edwards, 2013; Phillips, 2009; Pinotti, 2011). Einfühlung, or "feeling into", initially referred to the capacity of humans to project themselves into objects and feel their subjective quality. It was with Lipps (1903) and with the English use of the term by Titchener $(1909,1924)$ that empathy started to be used also to indicate the capacity for understanding other human beings. Definitions and critiques of empathy have been provided from psychoanalytic, historical and cultural perspectives as well. Freud (1921) referred to Einfühlung as a process distinct from identification or projection and through which we come to know and take position toward the existence of a psychic life different from ours. Simmel (1892) and Dilthey (1961) suggest that empathy is necessary for the historical reconstruction of events and protagonists of the past. 
Whereas Geertz (1983) highlights the intercultural limits of this concept.

Currently, despite the fact that definitions are only partially consistent, empathy is often considered a form of self-other overlapping that optimizes intersubjective transactions. Multifaceted models of empathy include: (a) a cognitive facet, entailing the two faces of perspectivetaking and fantasy, meaning that the observer spontaneously adopts the other's perspective, and activates internal reproduction or internal simulation of their perceived states respectively (Batson, Early, \& Salvarani, 1997; Cruz \& Gordon, 2003; Davis, 1983; Goldman, 2006). (b) an affective facet, which suggests empathic concerns and personal distress as key processes behind empathy. In this second facet, a control process is needed to avoid that seeing the difficulty of the others activates personal distress resulting in aversive or escaping reactions, or at best in egoistic helping behavior (i.e., empathy-altruism hypothesis, Batson, Duncan, Ackerman, Buckley, \& Birch, 1981). Such regulatory mechanisms are based on detachment and emotion regulation mechanisms that activate responses based both on understanding of others and on individual differentiation from them (Decety \& Jackson, 2004). Despite acknowledging that empathy should be treated as a unitary concept, other authors suggest slightly different facets. In particular, Baron-Cohen and Wheelwright (2004) suspect that the four sub-dimensions may identify processes broader than empathy. In particular, processes such as imagination or emotional self-control, although probably correlated with empathy, could express different features from empathy. It is worth noting, moreover, that the interaction between traits and states affect empathy. The former (i.e., traits) refer to stable capacity and ability of individuals, and are connected with inter-individual variances and their determinants, gender above all. The latter (i.e., states) refer to the situational variation of empathic response due to differences in contexts and stimuli. In this sense, imagination and emotion regulation could both be interpreted as stable individual capacities and as processes activated in specific social interactions.

Based on an extensive review, Cuff, Brown, Taylor, and Howat (2016) crafted the following definition:

Empathy is the emotional response (affective), dependent upon interaction between trait capacities and state influences. Empathic processes are automatically elicited but are also shaped by top-down control processes. The resulting emotion is similar to one's perception (directly experienced or imagined) and understanding (cognitive empathy) of the stimulus emotion, with recognition that the source of the emotion is not one's own. (Cuff et al., 2016, p. 7).

\section{Empathy with objects, animals, and robots}

Clearly, definitions of empathy initially addressed human beings. An intriguing question, however, is whether and how we humans are dispositionally ready to infer that animals, objects and now robots have some sort of mental states in common with us, and how situational variations affect these tendencies (Levin, Killingsworth, Saylor, Gordon, \& Kawamura, 2013).

Empathy with animals has been widely recognized and studied (e.g., Taylor \& Signal, 2005). For example, Paul's (2000) survey ( $N=514$ adults) on measuring empathy with humans and with animals revealed that these two forms of empathy were modestly correlated, indicating that they are unlikely to tap a single, unitary construct. In particular, it seems better to conceive empathy towards animal as a spectrum of responses that are activated by four independent characteristics: Agency (including the ability of animal to play, groom, display roles and behaviors comparable to human ones), Affectivity (i.e., animal's ability to show emotion); Coherence (i.e., the perception that the animal is a complex but well-defined whole, with arms, legs, body, face, and especially eyes), Continuity (i.e., the time spent with a given animal). In this line of research, the large amount of studies that focus on pets and mammals should be integrated by studies on other species, and in contexts that allow different degrees of continuity (Young, Khalil, \& Wharton, 2018). Induced and dispositional empathy with nature as a whole is also relevant in promoting empathy towards animals and pro-environmental behaviors at large (Tam, 2013). The type of humans-animals relationship also affects empathy: research shows, for example, that first year students in veterinary have higher levels of empathy compared to students at the end of their university studies, men showing more instrumental attitudes than women (Colombo, Pelosi, \& Prato-Previde, 2016). Angantyr, Eklund, and Hansen (2011) further showed gender differences: women reported significantly more empathy with animals than with humans. This latter study also analyzes empathy towards objects and shows that a human-like object (a puppy) can elicit the same degree of empathy as a baby.

This is coherent with Misselhorn (2009), who concluded that we feel a form of empathy with inanimate objects involving a kind of imaginative perception. This process has been largely recognized by the social sciences (Appadurai, 1986; Barthes, 1957; Douglas \& Isherwood, 1979). Knorr Cetina observed that in modern societies there is an "increased orientation toward objects as sources of the self, of relational intimacy, of shared subjectivity and social integration." (1997, p. 32).

A key to understanding perception of overlapping between humans, objects, animals and robots is the research on mind perception conducted by Gray, Gray, and Wegner 
(2007). Authors suggest that human and non-human actors are differentiated on the basis of the perceived experience (i.e., feeling hunger, fear, pain, pleasure, rage, desire, personality, consciousness, pride, embarrassment, and joy) and agency (i.e. self-control, morality, memory, emotion recognition, planning, communication, and thought). Experience is linked to perceived moral rights and privileges, whereas agency is linked to perceived moral agency and responsibility. Whereas humans are perceived to be high in both dimensions, animals like dogs are considered high in experience and low in agency, and robots are perceived to be high in agency and low in experience.

Thus, we should experience empathy only for animals (which have experience and moral rights, see for example Nagel, 1974; Premack \& Woodruff, 1978) but not for robots or inanimate objects (which do not have experience, but only moral responsibility). However, the specific characteristics of social robots disconfirm these expectations. The Computers As Social Actors (CASA) theoretical perspective (Liu \& Sundar, 2018; Nass, Steuer, \& Tauber, 1994; Reeves \& Nass, 1996) suggests that users of robotic agents know that they are inanimate but treat them socially nonetheless. Riek et al. (2009) explored whether the degree of anthropomorphism of the robots' appearance affected empathy with them. They showed that people are more empathetic with humanlike robots than with robots that were more machine-like in appearance. On a neurological level, Rosenthal-von der Pütten et al. (2014) showed that neuronal patterns of activation in human observers of video clips of social interaction between humans and other humans $v s$. humans with robots did not differ when the interaction was affectionate, but they did differ when it was violent and abusive. This result suggested that we can differentiate between humans and robots in some interactions but not in others. Additionally, mixing empathy with robots and with animals, Okita (2013) showed that, by using zoomorphic robots as social agents, strong, empathetic resonance is triggered. Finally, Küster, Swiderska, and Gunkel (2020) showed that human-like abilities, in comparison with the shape of the robot, more significantly impact mind perception, a process that is suggested to play an important role in empathic concern. Indeed, in the case of robot abuse, empathy seems to take place when we perceive that there is a mind which is able to carry out harmful behavior and a mind that is able to perceive it.

\section{Aims}

The purpose of this study is to explore differences and factors affecting empathy toward robots in comparison with inanimate objects, animals, and human actors. Here we present the cognitive empathy results (the affective empathy results are published by Mattiassi, Sarrica, Cavallo and Fortunati, 2019). Drawing on the related literature, we hypothesize that the perceived overlap between self and other objects affects individuals' perspective taking and activation of internal simulation of their affective state.

In particular, based on Gray et al. (2007), we expect more empathy toward living beings who are high in experience (humans and pets) than toward objects that are low in experience (social robots and inanimate objects).

Moreover, we expect also to find differences in the empathic reactions elicited by objects depending on their shapes. Indeed, the various degrees of anthropomorphism or zoomorphism that robots have could activate different degrees of empathy. Based on the examined literature (Angantyr et al., 2011; Paul, 2000; Riek et al., 2009; Young et al., 2018), we expect more empathy towards social robots that simulate human, coherent animal shapes, followed by robots with machine-like or geometric shapes, and finally by inanimate geometrical objects.

\section{Materials and methods}

\section{Participants}

A total of 163 respondents (95 males, 67 females, and 1 unidentified; age $20.09 \pm 2.28$ years) participated in this study. Respondents were all students enrolled in similar degrees programs at the University of Udine, with similar levels of education and unmarried. They were invited to participate during lessons, they participated freely, without any form of compensation.

\section{Stimuli}

In order to examine the different reactions elicited by anthropomorphic, zoomorphic and geometric robots, as compared with pets and humans we selected seven videos with different typologies of subjects. In line with the CASA paradigm, these elements can be considered Social Actors and can be classified according to their level of experience (from low to high capacity to feel, Grey et al., 2007) and their shape (anthropomorphic, zoomorphic, geometric) (Fig. 1).

The videos included a human, a cat, an anthropomorphic robot with a bipedal human structure ("Atlas" by Boston Dynamics), a four-legged robot resembling the structure of a mammal ("Spot" by Boston Dynamics), a robot half-way between the Roomba and the Mars Rover, a smartphone, and a Rubik cube. The Boston Dynamics videos have been also used in Küster et al. (2020), in which authors studied mind perception and morality of robot abuse.

Each video consists of a 2-s clip, in which a human interacts negatively (pushing, thrusting, or throwing) with another social actor. Male humans were performing the 
Fig. 1 The experience/shape Cartesian plane on which the seven selected Social Actors (SAs) are represented

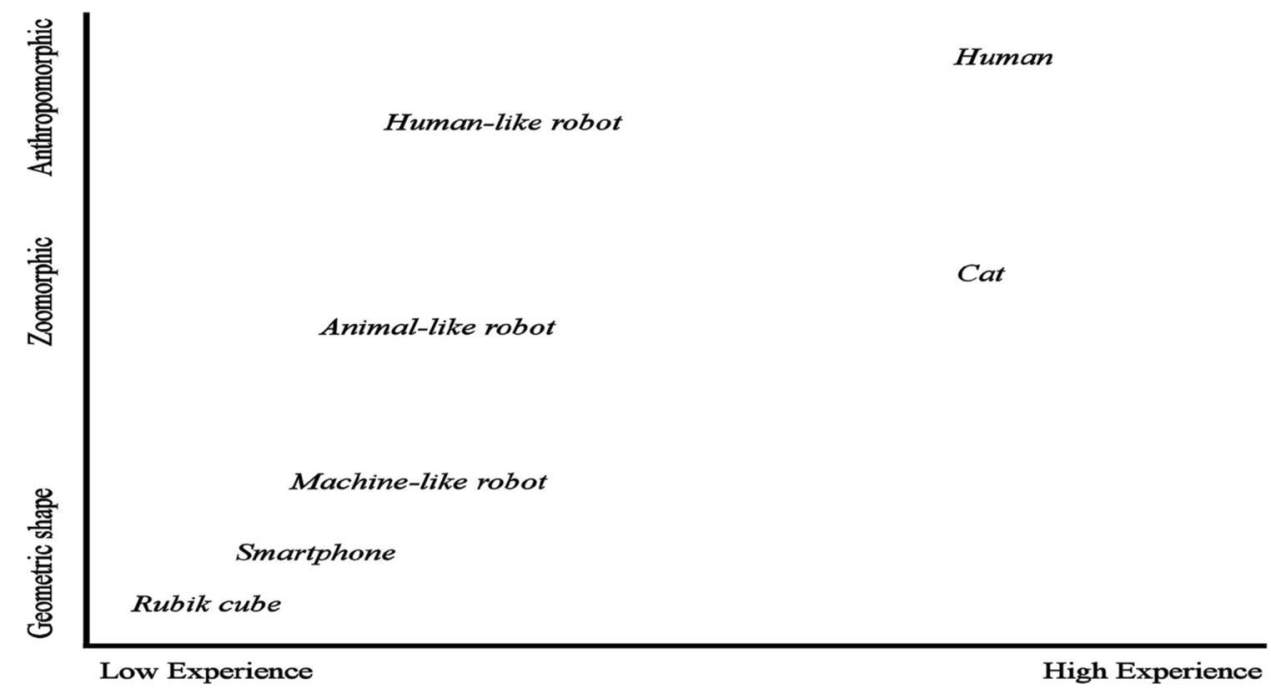

actions. They were fully visible only in the human-pushinghuman, and human-pushing-anthropomorphic robot video clips, in the other video clips only the foot was visible while pushing the cat, the zoomorphic robot, the machine-like robot, the Rubik cube or the hand throwing the smartphone.

\section{Procedure}

First, in order to examine dispositional empathy, at least in terms of individual beliefs about their own empathy, each participant completed the Empathy Quotient scale (EQ; Baron-Cohen \& Wheelwright, 2004). This measure, largely used with adult and clinical populations, has been recently applied in a number of studies on empathetic concern with social robots suggesting no effects of empathy on very basic images (e.g. e scissor potentially cutting a robotic finger) bur more nuanced effects for respondents with high levels of empathy, who tend to perceive robots as social agents (Rossi et al., 2020; Seo, Geiskkovitch, Nakane, King, \& Young, 2015; Suzuki, Galli, Ikeda, Itakura, \& Kitazaki, 2015). EQ shows convergent and discriminant validity with other measures (namely the IRI index, Davis, 1980). It differentiates between cognitive empathy, social skills and reactivity components, giving a different emphasis to the connection between perspective taking and affective dimensions on cognitive aspects, and not considering fantasy as a proper empathic process (Lawrence, Shaw, Baker, Baron-Cohen, \& David, 2004). The Italian version of the scale was applied (for details on validation see Preti et al., 2011).

The video clips were then presented sequentially in three university classrooms, projected on a screen. The presentation order of the videos was partially randomized and resulted in three different orders. ${ }^{1}$

After each video clip, the participants completed two selfevaluation tasks.

The first task aimed to investigate with a single item how much participants felt sorry for each mistreated object/person ("How sorry do you feel for the object or person that was a victim of the action?", 6-point Likert scale).

The second task was the Self-Assessment Manikin (SAM; Lang, 1980) a self-assessment on a 9-point visual scale of valence (from unhappy to happy), arousal (from relaxed to activated), and dominance (from lack of control to fully in control). Participants were asked to rate themselves and the other object/person on each of the three dimensions ("While watching this video clip I feel..." and "While watching this video clip I imagine that the object or person feels...”).

Finally, the questionnaire included a familiarity section in which we asked for the ownership, and usage of several objects similar to the one presented in the video: smartphone, a cat, Siri or Cortana, Roomba, Bimby, a robotic arm, a robotic lawnmower, and a Rubik cube. Additionally, a control item investigated the emotional attachment to the smartphone and the Rubik cube on a 5-point scale.

\footnotetext{
1 Videos had the following order: (1) animal-like robot, Rubik's cube, human-like robot, machine-like robot, cat, smartphone, and human; (2) human-like robot, animal-like robot, machine-like robot, Rubik cube, human, smartphone, and cat; (3) machine-like robot, human-like robot, human, smartphone, cat, Rubik's cube, and animallike robot. The videoclip order did not affect the general pattern. Only the third order, which started from the mechanical robot, shows a significant difference only for the evaluation of the cat videoclip.
} 
Table 1 Mean and standard deviation values for each SAM scale for each SA

\begin{tabular}{|c|c|c|c|c|c|c|}
\hline & \multicolumn{2}{|c|}{ Valence } & \multicolumn{2}{|c|}{ Arousal } & \multicolumn{2}{|c|}{ Dominance } \\
\hline & Mean & s.d. & Mean & s.d. & Mean & s.d. \\
\hline Rubik's cube & 5.31 & 0.16 & 2.73 & 0.24 & 7.36 & 0.26 \\
\hline Smartphone & 5.21 & 0.12 & 2.56 & 0.21 & 7.43 & 0.25 \\
\hline Machine-like robot & 5.31 & 0.10 & 2.57 & 0.21 & 7.53 & 0.22 \\
\hline Animal-like robot & 4.39 & 0.13 & 3.74 & 0.24 & 7.11 & 0.23 \\
\hline Human-like robot & 4.66 & 0.13 & 3.37 & 0.24 & 7.22 & 0.21 \\
\hline Cat & 3.13 & 0.15 & 5.72 & 0.22 & 5.68 & 0.23 \\
\hline Human & 4.23 & 0.12 & 4.22 & 0.21 & 6.78 & 0.20 \\
\hline
\end{tabular}

\section{Data handling}

Data were submitted to ANOVAs and to a 7 (video) $\times 12$ (familiarity items) $\times 3$ self/other delta on each SAM scale (valence, arousal, dominance) MANOVA. The seven video stimuli (human; human-like robot; animal; animal-like robot; machine-like robot; Rubik cube; smartphone) were variables within participants; and video order (order 1 vs. order 2 vs. order 3 ) and empathy level (high vs. low) were variables between participants.

The evaluation of valence, arousal, and dominance attributed to the other (i.e., the SAM scale) for each stimulus was computed (Table 1) and entered as dependent variables in ANOVAs, the discrepancy between self and other evaluation was entered as dependent in the MANOVA.

An additional MANOVA was run for answers to the "How sorry do you feel for the object or person that was a victim of the action?" item as a dependent variable with the same categorical predictors.

Reliability of EQ was controlled first. The EQ scores were computed and mean scores are in line with those reported in the literature $(\min =14 \max =59$; Mean 38.8, $\mathrm{SD}=9.57)$. However, only one of the subscales of the EQ turned out to be reliable (alpha $>.70$ ). The remaining subscales, that is emotional reactivity and social skills turned out to be unreliable. It can be noted that the item included in the "cognitive empathy" subscale (items 1, 19, 22, 25, 26, 36, 41, 43, $44,52,54,55,58$, and 60 ) is a complex measure of the appreciation of affective, epistemic and desire-based states (Lawrence et al., 2004; Preti et al., 2011; Senese et al., 2018, De Nicola, Passaro, \& Ruggiero, 2016). This is the most relevant subscale to our purposes, since the other should assess individual reactions to others, and capacity to reactivity and personal ability in social situations. Despite this severe limitation, we thus performed the analysis only on the so called cognitive sub-dimension of the EQ. A median split was applied to identify respondents with high $(\geq 16)$ vs. low $(<16)$ dispositional empathy.

Finally, familiarity items, along with gender, were entered as categorical variables (with the exception of the item asking for the use of smartphones, which had no variance since all participants answered "yes").

Data were analyzed using the StatSoft Statistica 10 package (Statistica, Tulsa, Oklahoma). Post-hoc multiple, pairwise comparisons were performed for the ANOVAs, while post-hoc discriminant analysis was conducted for the MANOVAs. Bonferroni was applied to correct for multiple comparisons. A significance threshold of $p<.05$ was set for all statistical analyses.

\section{Results}

\section{Self-assessment of emotions felt by objects and persons}

Analysis of the SAM answer to the question "While watching this video clip I imagine that the object or person feels...", was performed over 162 participants after casedeleting for missing data. Results did not highlight particularly relevant differences among groups. Differences in ratings for each of the three scales is not significant (all $p$ s > .088). Significant differences $\left(F_{(2,312)}=3.31, p=0.038\right)$ emerge as regards the discrepancy between attributed dominance, valence and arousal, which is more neat for the highempathy group, as shown in Fig. 2.

The interaction between video order and typology of social actor $\left(F_{(12,936)}=5.77, p<.001\right)$, SAM scales $\left(F_{(4,312)}=11.64, p<.001\right)$, and the triple interaction between video order, actor, and SAM scales $\left(F_{(24,1872)}=2.00\right.$, $p=.003)$ all reached significance. Post-hoc comparisons of the triple interaction revealed arousal ratings were higher in the 1 st video order than in the 3 rd video order for the mistreated Rubik cube $(4.38 \pm 0.25$ vs. $2.29 \pm 0.53, p=.007)$ and for the human $(5.17 \pm 0.22$ vs. $2.88 \pm 0.46, p<.001)$. When the animal-like robot was presented first (1st order) it was attributed lower dominance ratings compared to the other conditions (2nd and 3rd order): $5.86 \pm 0.26$ vs. $7.43 \pm 0.46$, $p=.049$; and vs. $8.79 \pm 0.56, p<.001)$. Valence was unaffected by video order. 


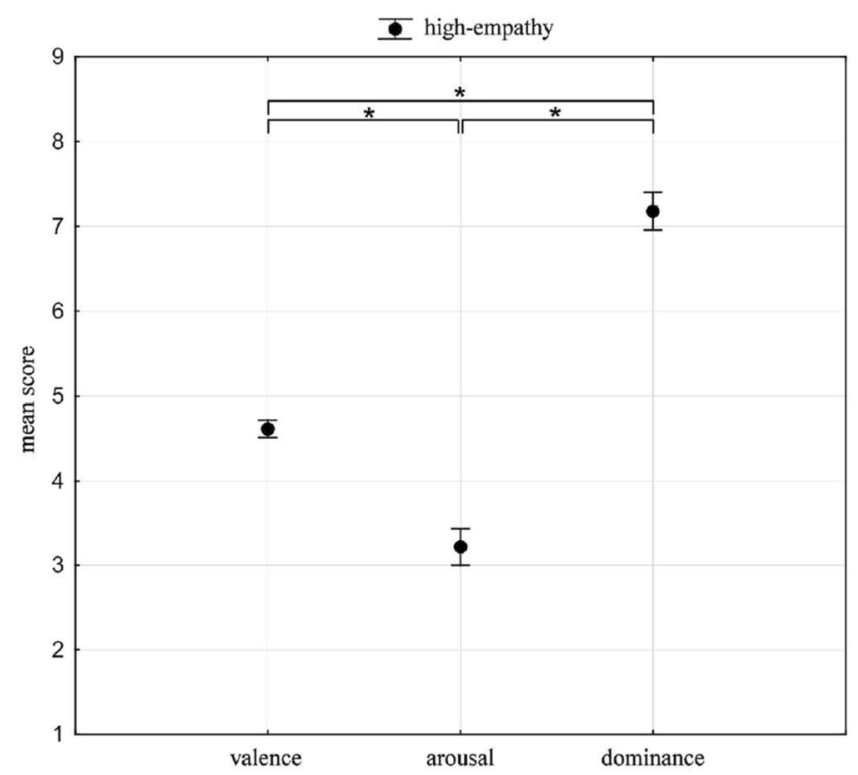

Fig. 2 Differences in empathy levels of each of the SAM scale for High empathy and Low empathy groups. Note: Groups with different empathy levels scored differently: valence and arousal scores did dif-

As such, since our main interest was to assess the effect of observing mistreated persons, robots or objects, the interaction between attributed states (SAM) and typology of actors were analyzed without the video order factor. Results show significant effects $\left(F_{(12,1872)}=39.58, p<.001\right)$.

Post-hoc comparisons of the valence ratings (from sad to happy) showed that participants attributed similar valence to emotions felt by the mistreated actors, except for the cat and the human. The affective state attributed to human was slightly more negative $(4.23 \pm 0.12)$, and differed significantly from the scores given to the Rubik's cube $(5.31 \pm 0.16 ; p=.001)$, the machine-like robot $(5.31 \pm 0.1$; $p<.001)$, and the smartphone $(5.21 \pm 0.12 ; p<.001)$. The affective state attributed to the cat was much more negative $(3.13 \pm 0.15)$ and differed from those of all other SAs (all ps $<.001)$.

Post-hoc comparisons of the arousal ratings (from relaxed to activated) showed an analogue but reverse pattern: the arousal attributed to the cat $(5.72 \pm 0.22)$ was significantly higher than all other SAs' scores (all ps $<0.001$ ). The remaining comparisons correspond to hypothesized different levels of experience of the actors (Fig. 1): the arousal attributed to the human $(4.22 \pm 0.21)$ was higher than most other SAs $(p<0.005)$ with the exception of the animal-like robot $(3.74 \pm 0.24, p=0.11)$; following, the human-like robot $(3.37 \pm 0.24)$ and the animal-like robot $(3.74 \pm 0.24)$ were attributed more activation than the remaining SAs (all ps $<0.01$, human-like robot vs. Rubik cube $p=0.067$ ); finally, the lowest scores were attributed to a third cluster

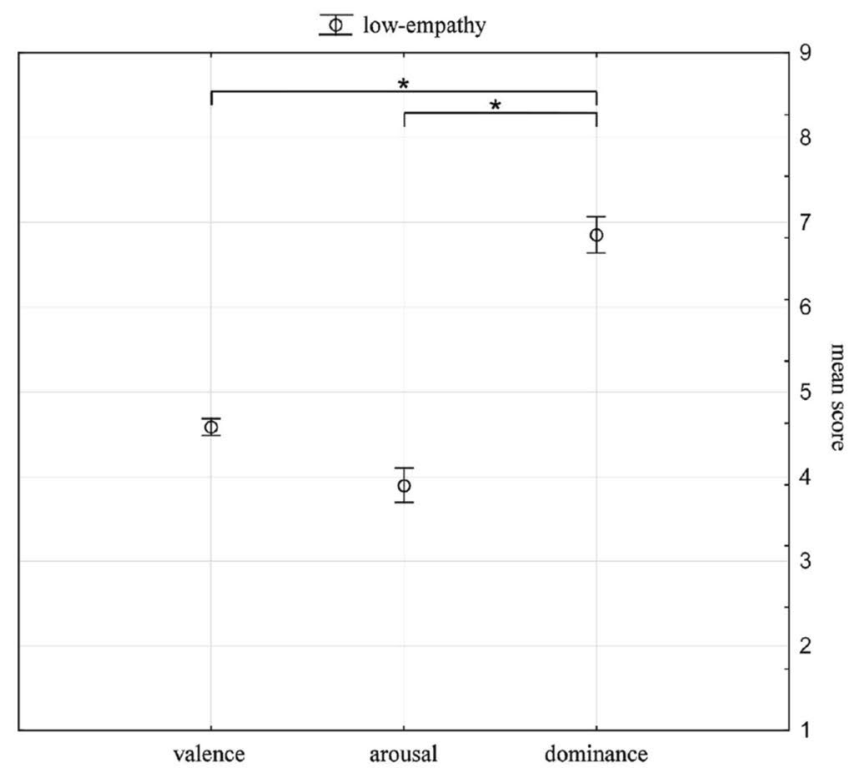

fer in the high-empathy group but did not differ in the low-empathy group. * indicates a significant difference

including the Rubik's cube $(2.73 \pm 0.24)$, the machine-like robot $(2.57 \pm 0.21)$ and the smartphone $(2.56 \pm 0.21)$.

The post-hoc comparisons on the attributed dominance scale showed, again, that to the cat was attributed less control $(5.68 \pm 0.23)$ than to all other SAs (all $p s>.002)$. The other significant differences with scores attributed to the human $(6.78 \pm 0.2)$ that survived Bonferroni correction were limited to the Rubik cube $(7.36 \pm 0.26 ; p=.011)$ and the machine-like robot $(7.53 \pm 0.22 ; p=.005)$ score. The remaining SAs all scored high in dominance values (mean $7.33 \pm 0.23$ ). Results for all SAM scales are presented in Fig. 3.

\section{Familiarity: a recurring factor predicting congruence between perception of self and others' condition}

A direct comparison between self and other condition (see Mattiassi et al., 2019 for complete description of valence, arousal and dominance attributed to the self) shows that evaluations were mostly congruent in the valence dimension $(4.35 \pm 0.15$ vs. $4.61 \pm 0.13)$, but participants felt much more activated than they thought the other persons/robots/ objects were $(4.64 \pm 0.22$ vs. $3.53 \pm 0.23)$. The dominance evaluations were even more incongruent: participants felt they were much less in control than they thought the mistreated actors in the video were $(5.62 \pm 0.22$ vs. $7.05 \pm 0.23)$.

The factors that predict congruence between self and other perception are familiarity and gender. MANOVAs 
Fig. 3 Valence (a), arousal (b) and dominance (c) scores for each SA, compared to the scores attributed to the human (dotted line for reference). * indicates a significant difference with the human scores. @ (cat) indicates a significant difference from all other SAs, in addition to the significant difference with the human. On the right of each figure, the extremes of the SAM scales, corresponding to the scores "1" and "9"
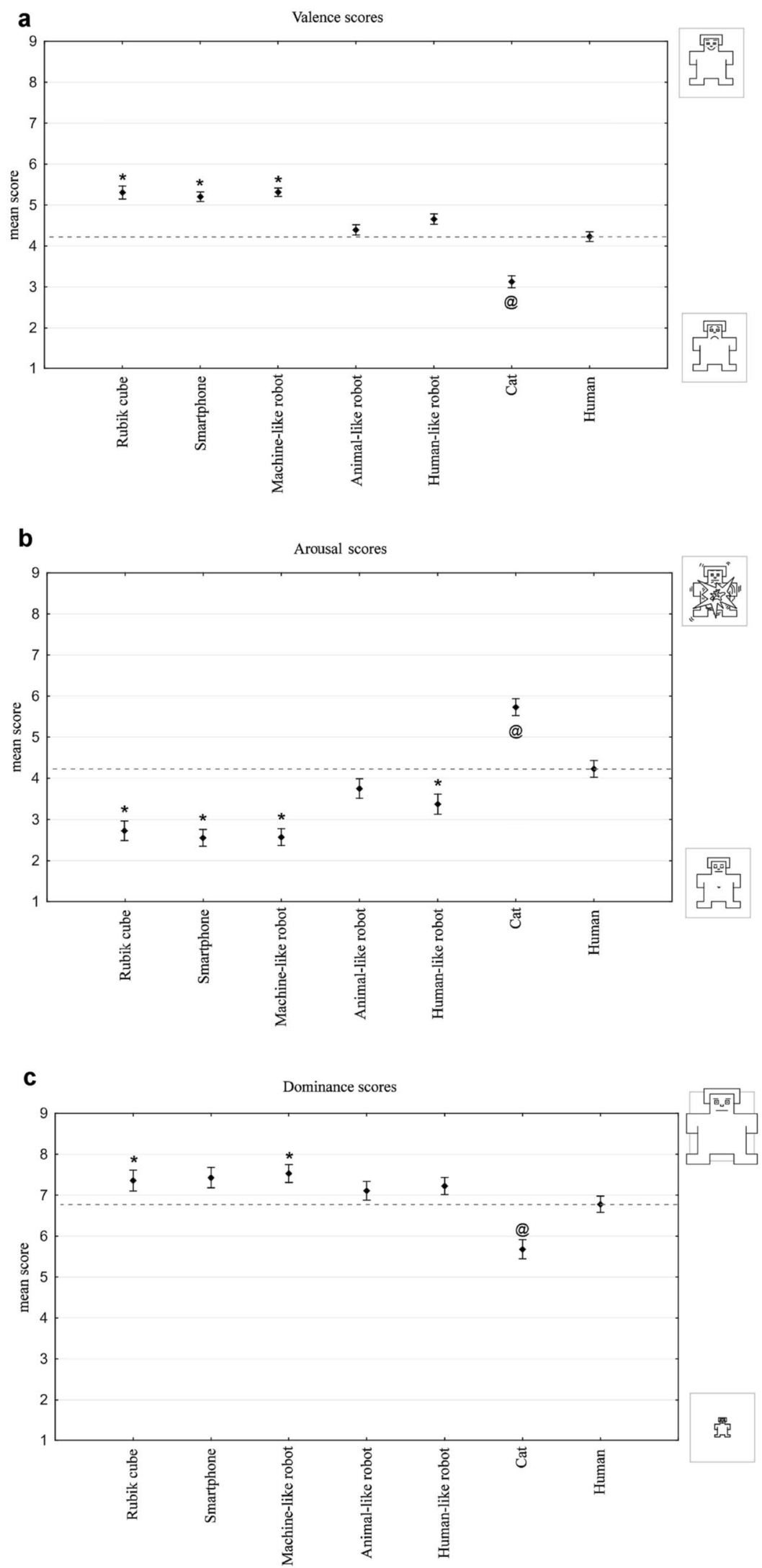
were conducted on 158 participants after deletion for incomplete data. Wilk's Lambda test was used for the MANOVAs. Since MANOVA uses data-controlled variables, only observed data are reported.

The MANOVA for the "How sorry do you feel for the object or person that was a victim of the action?" showed that gender $\left(F_{(7,142)}=2.42, p=.022\right)$ was a main factor predicting how much participants felt sorry for the others. Post-hoc discriminant analysis revealed males $(2.09 \pm 0.15)$ felt less sorry than females $(2.84 \pm 0.18)$ for the animallike robot $(p=.034)$ but felt more sorry $(1.48 \pm 0.09)$ than females $(1.37 \pm 0.11)$ for the machine-like robot $(p=.037)$. Moreover, Roomba usage also predicted participant responses $\left(F_{(7,142)}=2.43, p=.022\right)$ as Roomba users $(2 \pm 0.19)$ felt more sorry than non-users $(1.34 \pm 0.07)$ for the machine-like robot $(p=.005)$.

The MANOVA on valence showed a number of tendencies toward significance (gender, $p=.080$; familiar use of a robotic arm, $p=.090$ ), but the only factor that significantly predicted congruence was the familiar use of the Bimby cooking robot $\left(F_{(7,142)}=3.1, p=.004\right)$. Post-hoc discriminant analysis showed that those familiar with it $(-1.49 \pm 0.4)$ were more congruent in valence evaluations with the animal-like robot $(p=.011)$ than those who were not famil$\operatorname{iar}(-2.58 \pm 0.24)$. Interestingly those unfamiliar with the Bimby $(0.17 \pm 0.15)$ gave more congruent evaluation on valence between self and the mistreated human $(p=.018)$ than those who were not $(0.7 \pm 0.25)$. The arousal MANOVA did not yield any significant results (all $p s>.200$ ). The dominance MANOVA showed different, significant, predicting factors: cat ownership, familiarity with robotic lawnmowers, and having tried to solve a Rubik's cube. Participants owning a cat $(-0.89 \pm 0.39)$ perceived less congruence than those who do not $(0.14 \pm 0.43)$ in the dominance evaluations for the smartphone $(p=.010)$. The significance of the lawnmower ownership effect did not survive the post-hoc analysis, and neither did the cube solving one.

In general, the analysis of familiarity shows some links between familiarity with robots and being more empathic with them, as well as being more congruent in attributedevoked feelings when looking at them in comparison to less congruence with humans. Cat ownership predicted more incongruence with the smartphone. These results need to be expanded upon in future inquiries.

\section{Discussion}

This study aimed at exploring the factors that affect perceived empathy toward different kinds of robots, inanimate objects, animals, and human actors. We hypothesized that empathy depends to some degree on the perceived self/ other overlap, expecting that two main dimensions could be relevant to describe it. The first dimension is experience, defined as the ability to experience the effect of the environment on oneself (Gray et al., 2007). Regarding experience, we expected more empathy toward living beings that are high in experience (humans and pets), a lesser degree of empathy toward animate objects that are low in experience (social robots), and the lowest values of empathy toward inanimate objects. The second dimension is the degree of anthropomorphism or zoomorphism that is conveyed by their shape. This simulates the capacity to have a mind because we expect minded entities to have shapes similar to those of entities to which we already attribute a mind such as humans and, to a lesser degree, animals. Our hypothesis, in accordance with the examined literature (Angantyr et al., 2011; Paul, 2000; Riek et al., 2009), was to find differences in the empathic reactions elicited in humans by varying those others that are expected to elicit them. Specifically, we looked at attributed states and compared them with previous studies on self-reported states looking at mistreated others (Mattiassi et al., 2019).

The most relevant result of our previous study (Mattiassi et al., 2019) was that participants felt more empathy (on all SAM scales, as well as feeling sorry for) with the cat than with all other actors, humans included. In this study a similar result has emerged by looking at the attributed feelings. Participants attributed to the cat itself emotions that were more negative and activating, and attributed to the cat less control. Consequently in the case of the cat, we found the same pattern for evoked and attributed feelings.

In Mattiassi et al. (2019) it was also found that participants empathize more with mistreated entities resembling living beings than with mistreated robots or objects (i.e. they felt more negative valence, more arousal, less dominance, more sorry for living beings). The present analysis of attributed emotions, however, yields different results. Participants attributed emotional valence that was neutral (halfway through happy and sad) to all the others except the human and the cat, whose emotions received more negative evaluations. This result suggests that valence may be a feature that is distinctively attributed to alive social actors, who have higher levels of experience. Participants felt negative emotions when looking at mistreated others, but attributed the same feelings only to high-experience actors.

Similarly, arousal evaluations correspond to an attributed degree of experience: the cat and the human being attributed more activating emotions, followed by human-like and animal-like robot, again followed by the machine-like robot, the smartphone and the Rubik's cube.

Finally, the results for dominance were replicated in that the cat's emotions received lower scores, pointing again at a specificity of this pet, who is perceived as not being in control and thus completely victimized. 
Since the present analysis focuses on the cognitive aspect of empathy, one interesting result was to relate general response patterns to one's own empathic level as measured by the EQ cognitive subscale. Respondents with lower levels of empathy reported higher attributed dominance than valence and arousal scores, focusing on the agentivity of the actor in the video rather than focusing on the emotions per se. Conversely, the higher empathizers reported lower attributed arousal, focusing on the inferred activation that the situation caused in the victim. Despite being preliminary this result might shed light on what high vs. low dispositional empathy means for the attributing mental states to lifelike and alive others.

Finally, we highlighted the effect that the familiarity with robots had on subject responses. The analysis shows that familiarity with some robotic artefacts of everyday use is related to being more empathic and more congruent in attributed-evoked feelings, as well as some other minor relations that need to be further explored. While we used familiarity to control for unexpected results in this study, it might be worthwhile to further explore and expand on these findings to better understand how daily usage of technology affects empathy.

In light of a future environment in which robots are considered social partners, correctly predicting empathy, as well as mind perception and morality towards them, seems very important. This study adds depth to the understanding of our relationship with robots. Our results are in line with previous studies on empathy toward robots that suggested how perceived experience modulates empathy, and specifically predicts how more empathy is perceived towards humanlike and animal-like robots (Angantyr et al., 2011; Küster et al., 2020; Paul, 2000; Riek et al., 2009; Young et al., 2018) in comparison with machine-like robots or inanimate objects. However, by comparing different shaped robots with animals, humans and inanimate objects, we expanded this literature by directly comparing different domains (alive, robotic, inanimate). Indeed, in our opinion, empathy needs to be studied across domains to be applicable in a future in which the line between lifelike and alive will be more blurred (Darling, 2016) and robots are expected to be perceived as social interaction partners. Ethical concerns will probably arise accordingly, and being able to predict if our ability to perceive empathy will be impacted by this possibility seems crucial.

However, caution in generalization is warranted since the present study has several limits. Our stimuli should have been designed more appropriately to be more comparable, for example by using the same exact action on all victims, or by controlling for effects of similarity between actors (perpetrators and victims) on screen and observers, such as gender (Batson, Lishner, Cook, \& Sawyer, 2005)—indeed, all recognizable perpetrators in the video clips were male.
Additionally, the order of video clips and of items in the questionnaire, and particularly in the dependent variables has not been fully randomized in order to control for order effects. Finally, and most important, in this study we followed some recent research using EQ as a measure. Some variability in the items loading on the three subscales of the Italian version of the EQ was already reported in the literature (Senese et al., 2018). However, according to our data, only the first sub-scale defined as cognitive empathy proved reliable, and this has limited the extent to which we could grasp different facets of empathy. The use of different scales or the use of EQ in conjunction with alternative measures such as IRI subscales (Lawrence et al., 2004) could have provided a more refined understanding of the different nuances of empathy involved in human-animal-robots interactions. Finally, in respect to empathy, which is a complex theoretical construct, here we stressed the cognitive and perspective taking aspect, while neglecting the emotional facet. A thorough exploration of empathy should have considered emotions.

Despite these limitations, the main contribution of this paper lies in a direct comparison between subjects from a wide range of different domains (human, animals, different types of robots and inanimate objects) that previous studies missed. Indeed, we explored for the first time how empathy with mistreated subjects-including robots with a different appearance of anthropomorphization, zoomorphization, machine-likeness, as well as different perceived experience, is modulated by our perceived overlap between ourselves and the other, and how vicarious and attributed feelings vary depending on dispositional and situational factors. Our results on robots are particularly interesting: given the continuous technological advances that are transforming robots and our cultural and ethical relationships with them, further studies could elaborate and develop this line and deepen the regulatory modes of these new forms of interactions.

Acknowledgements We want to thank the members of the NuMe Lab (University of Udine) for supporting the logistics of data collection. We also want to thank students of the "Laboratorio di Social Robotics" course who provided help for all phases of the study. Finally, we thank the "Azienda per l'assistenza sanitaria n. 5 'Friuli occidentale", that promoted the research project "Sciences and Technologies for Cognitive Disabilities" within which the present study was co-designed.

Funding Open access funding provided by Università degli Studi di Firenze within the CRUI-CARE Agreement. This research did not receive any specific grant from funding agencies in the public, commercial, or not-for-profit sectors.

\section{Declarations}

Conflict of interest The authors declare that they have no conflict of interest.

Open Access This article is licensed under a Creative Commons Attribution 4.0 International License, which permits use, sharing, 
adaptation, distribution and reproduction in any medium or format, as long as you give appropriate credit to the original author(s) and the source, provide a link to the Creative Commons licence, and indicate if changes were made. The images or other third party material in this article are included in the article's Creative Commons licence, unless indicated otherwise in a credit line to the material. If material is not included in the article's Creative Commons licence and your intended use is not permitted by statutory regulation or exceeds the permitted use, you will need to obtain permission directly from the copyright holder. To view a copy of this licence, visit http://creativecommons. org/licenses/by/4.0/.

\section{References}

Angantyr, M., Eklund, J., \& Hansen, E. M. (2011). A comparison of empathy for humans and empathy for animals. Anthrozoos, 24(4), 369-377. https://doi.org/10.2752/175303711X13159027359764

Appadurai, A. (Ed.). (1986). The social life of things: Commodities in cultural perspective. Cambridge University Press.

Barile, N., \& Sugiyama, S. (2015). The automation of taste: A theoretical exploration of mobile ICTs and social robots in the context of music consumption. International Journal of Social Robotics, 7(3), 407-416.

Barthes, R. (1957). Mythologies. Seuil.

Bartneck, C., Kanda, T., Ishiguro, H., \& Hagita, N. (2007). Is the uncanny valley an uncanny cliff? In 16th IEEE International Conference on Robot \& Human Interactive Communication (pp. 368-373). Jeju, Korea. https://doi.org/10.1109/ROMAN.2007. 4415111

Batson, C. D., Duncan, B. D., Ackerman, P., Buckley, T., \& Birch, K. (1981). Is empathic emotion a source of altruistic motivation? Journal of Personality and Social Psychology, 40(2), 290-302.

Batson, C. D., Early, S., \& Salvarani, G. (1997). Perspective taking: Imagining how another feels versus imaging how you would feel. Personality and Social Psychology Bulletin, 23(7), 751-758.

Batson, C. D., Lishner, D. A., Cook, J., \& Sawyer, S. (2005). Similarity and nurturance: Two possible sources of empathy for strangers. Basic and Applied Social Psychology, 27(1), 15-25.

Borenstein, J., \& Arkin, R. C. (2017). Nudging for good: Robots and the ethical appropriateness of nurturing empathy and charitable behavior. Ai \& Society, 32(4), 499-507.

Breazeal, C. (2002). Designing sociable robots. Intelligent robots and autonomous agents. MIT Press.

Breazeal, C. (2003). Toward sociable robots. Robotics and Autonomous Systems, 42(3), 167-175.

Brščić, D., Kidokoro, H., Suehiro, Y., \& Kanda, T. (2015, March). Escaping from children's abuse of social robots. In Proceedings of the tenth annual acm/ieee international conference on humanrobot interaction (pp. 59-66).

Bartneck, C., Rosalia, C., Menges, R., \& Deckers, I. (2005). Robot abuse-A limitation of the media equation. In A. De Angeli, S. Brahnam, \& P. Wallis (Eds.), Proceedings of the INTERACT '05 workshop on agent abuse (pp. 54-57). Rome, 12 September. http://hdl.handle.net/10092/16925

Brahnam, S., \& De Angeli, A. (2008). Special issue on the abuse and misuse of social agents. Interacting with Computers, 20(3), 287-291.

Broadbent, E. (2017). Interactions with robots: The truths we reveal about ourselves. Annual Review of Psychology, 68(1), 627-652.

Cavallo, F., Limosani, R., Manzi, A., Bonaccorsi, M., Esposito, R., Di Rocco, M., et al. (2014). Development of a socially believable multi-robot solution from town to home. Cognitive Computation, 6(4), 954-967.

Cavallo, F., Esposito, R., Limosani, R., Manzi, A., Bevilacqua, R., Felici, E., et al. (2018). Robotic services acceptance in smart environments with older adults: User satisfaction and acceptability study. Journal of Medical Internet Research, 20(9), e264.

Coeckelbergh, M. (2018). Why care about robots? Empathy, moral standing, and the language of suffering. Kairos. Journal of Philosophy \& Science, 20(1), 141-158.

Colombo, E. S., Pelosi, A., \& Prato-Previde, E. (2016). Empathy towards animals and belief in animal-human-continuity in Italian veterinary students. Animal Welfare, 25(2), 275-286.

Cruz, J., \& Gordon, R. M. (2003). Simulation theory. Nature Publishing Group.

Cuff, B. M. P., Brown, S. J., Taylor, L., \& Howat, D. J. (2016). Empathy. A review of the concept. Emotion Review, 8(2), 144-153. https://doi.org/10.1177/1754073914558466

Damiano, L., Dumouchel, P., \& Lehmann, H. (2015). Towards humanrobot affective co-evolution overcoming oppositions in constructing emotions and empathy. International Journal of Social Robotics, 7(1), 7-18.

Darling, K. (2016). Extending legal protection to social robots: The effects of anthropomorphism, empathy, and violent behavior towards robotic objects. Edward Elgar Publishing.

Dautenhahn, K., \& Billard, A. (1999). Bringing up robots or the psychology of socially intelligent robots: From theory to implementation. In: 3rd annual conference on Autonomous Agents, Seattle, 1999 (pp. 366-367). New-York: ACM.

Davis, M. H. (1980). A multidimensional approach to individual differences in empathy. JSAS Catalog of Selected Documents in Psychology, 10, 85.

Davis, M. H. (1983). Measuring individual differences in empathy: Evidence for a multidimensional approach. Journal of Personality and Social Psychology, 44(1), 113-126.

de Graaf, M. M., Ben Allouch, S., \& van Dijk, J. A. (2019). Why would I use this in my home? A model of domestic social robot acceptance. Human-Computer Interaction, 34(2), 115-173.

Decety, J., \& Jackson, P. L. (2004). The functional architecture of human empathy. Behavioral and Cognitive Neuroscience Reviews, 3(2), 71-100. https://doi.org/10.1177/1534582304267187

Dilthey, W. (1961). Meaning in history. Allen \& Unwin.

Douglas, M., \& Isherwood, B. (1979). The world of goods. Towards an anthropology of consumption. Basic Book.

Edwards, L. H. (2013). A brief conceptual history of Einfühlung: 18thcentury Germany to post-World War II US psychology. History of Psychology, 16(4), 269-281.

Ferrari, F., Paladino, M. P., \& Jetten, J. (2016). Blurring humanmachine distinctions: Anthropomorphic appearance in social robots as a threat to human distinctiveness. International Journal of Social Robotics, 8(2), 287-302.

Fiorini, L., Esposito, R., Bonaccorsi, M., Petrazzuolo, C., Saponara, F., Giannantonio, R., De Petris, G., Dario, P., \& Cavallo, F. (2017). Enabling personalised medical support for chronic disease management through a hybrid robot-cloud approach. Autonomous Robots, 41(5), 1263-1276.

Fong, T., Nourbakhsh, I., \& Dautenhahn, K. (2003). A survey of socially interactive robots. Robotics and Autonomous Systems, 42(3), 143-166.

Fortunati, L. (2013). Afterword: Robot conceptualizations between continuity and innovation. Intervalla, 1, 116-129.

Fortunati, L. (2018). Robotization and the domestic sphere. New Media \& Society, 20(8), 2673-2690.

Freud, S. (1921). Massenpsgychologie und Ich-Analyse. Internationaler psychoanalytischer Verlag. 
Gallagher, S. (2007). Social cognition and social robots. Pragmatics \& Cognition, 15(3), 435-453.

Geertz, C. (1983). Local knowledge: Fact and law in comparative perspective. Basic Books.

Goldman, A. I. (2006). Simulating minds: The philosophy, psychology, and neuroscience of mindreading. Oxford University Press.

Gray, H. M., Gray, K., \& Wegner, D. M. (2007). Dimensions of mind perception. Science, 315, 619. https://doi.org/10.1126/science. 1134475

Hegel, F., Muhl, C., Wrede, B., Hielscher-Fastabend, M., \& Sagerer, G. (2009). Understanding social robots. In Proceedings of the 2nd International Conferences on Advances in Computer-Human Interactions, Cancun, Mexico, IEEE (pp. 169-174).

Knorr Cetina, K. (1997). Sociality with objects. Social relations in postsocial knowledge societies. Theory, Culture \& Society, 14(4), 1-30. https://doi.org/10.1177/026327697014004001

Küster, D., Swiderska, A., \& Gunkel, D. (2020). I saw it on YouTube! How online videos shape perceptions of mind, morality, and fears about robots. New Media \& Society. https://doi.org/10.1177/14614 44820954199

Lang, P. J. (1980). Self-assessment manikin. The Center for Research in Psychophysiology: University of Florida.

Leite, I., Pereira, A., Mascarenhas, S., Martinho, C., Prada, R., \& Paiva, A. (2013). The influence of empathy in human-robot relations. International Journal of Human-Computer Studies, 71(3), 250-260.

Lipps, T. (1903). Einfuhlung, inner Nachahmung, und Organ-umpfindungen [Empathy, inner imitations, and sensations]. Archiv fur die Gesamte Psychologie, 2, 185-204.

Liu, B., \& Sundar, S. S. (2018). Should machines express sympathy and empathy? Experiments with a health advice Chatbot. Cyberpsychology, Behavior, and Social Networking, 21(10), 625-636. https://doi.org/10.1089/cyber.2018.0110

Löffler, D., Dörrenbächer, J., \& Hassenzahl, M. (2020). The uncanny valley effect in zoomorphic robots: The $\mathrm{U}$-shaped relation between animal likeness and likeability. In Proceedings of the 2020 ACM/ IEEE international conference on human-robot interaction (pp. 261-270).

Lawrence, E. J., Shaw, P., Baker, D., Baron-Cohen, S., \& David, A. S. (2004). Measuring empathy: Reliability and validity of the Empathy Quotient. Psychological Medicine, 34(5), 911.

Levin, D. T., Killingsworth, S. S., Saylor, M. M., Gordon, S. M., \& Kawamura, K. (2013). Tests of concepts about different kinds of minds: Predictions about the behavior of computers, robots, and people. Human-Computer Interaction, 28(2), 161-191.

Mattiassi, A. D., Sarrica, M., Cavallo, F., \& Fortunati, L. (2019). Degrees of empathy: Humans' empathy toward humans, animals, robots and objects. In N. Casiddu, C. Porfirione, A. Monteriù, F. Cavallo (Eds.), Ambient assisted living. Italian forum 2017, Lecture notes in electrical engineering (Vol. 540, pp. 101-113). Ambient Assisted Living.

Misselhorn, C. (2009). Empathy with inanimate objects and the uncanny valley. Minds and Machines, 19(3), 345-359.

Misra, S., Cheng, L., Genevie, J., \& Yuan, M. (2016). The iPhone effect: The quality of in-person social interactions in the presence of mobile devices. Environment and Behavior, 48(2), 275-298.

Mori, M. (1970). The uncanny valley. Energy, 7(4), 33-35. https://doi. org/10.1109/MRA.2012.2192811

Nass, C., Steuer, J., \& Tauber, E.R. (1994) Computers are social actors. In Proceedings of the SIGCHI Conference on Human Factors in Computing Systems (CHI'94) (pp. 72-78). Boston, MA: ACM.

Nagel, T. (1974). What is it like to be a bat? The Philosophical Review, 83(4), 435-450. https://doi.org/10.2307/2183914

Okita, S. Y. (2013). Self-other's perspective taking: The use of therapeutic robot companions as social agents for reducing pain and anxiety in pediatric patients. Cyberpsychology, Behavior, and
Social Networking, 16(6), 436-441. https://doi.org/10.1089/cyber. 2012.0513

Paul, E. S. (2000). Empathy with animals and with humans: Are they linked? Anthrozoos, 13(4), 194-202. https://doi.org/10.2752/ 089279300786999699

Pinotti, A. (2011). Empatia: Storia di un'idea da Platone al postumano. Laterza.

Phillips, C. (2009). The welfare of animals. The silent majority. Springer.

Premack, D., \& Woodruff, G. (1978). Chimpanzee theory of mind. Behavioral and Brain Sciences, 4, 515-526.

Preti, A., Vellante, M., Baron-Cohen, S., Zucca, G., Petretto, D. R., \& Masala, C. (2011). The Empathy Quotient: A cross-cultural comparison of the Italian version. Cognitive Neuropsychiatry, 16(1), 50-70.

Reeves, B., \& Nass, C. (1996). The media equation: How people treat computers, television, and new media like real people and places. CSLI Publications and Cambridge University Press.

Riek, L. D., Rabinowitch, T., Chakrabarti, B., \& Robinson, P. (2009). How anthropomorphism affects empathy toward robots. In Proceedings of the 4th ACM/IEEE international conference on Human robot interaction (pp. 245-246).

Rossi, S., Conti, D., Garramone, F., Santangelo, G., Staffa, M., Varrasi, S., et al. (2020). The role of personality factors and empathy in the acceptance and performance of a social robot for psychometric evaluations. Robotics, 9(2), 39.

Rosenthal-Von Der Pütten, A. M., Schulte, F. P., Eimler, S. C., Sobieraj, S., Hoffmann, L., Maderwald, S., Brand, M., \& Krämer, N. C. (2014). Investigations on empathy towards humans and robots using fMRI. Computers in Human Behavior, 33, 201-212.

Senese, V. P., De Nicola, A., Passaro, A., \& Ruggiero, G. (2018). The factorial structure of a 15 item version of the Italian Empathy Quotient Scale. European Journal of Psychological Assessment, 34(5), 344-351.

Seyama, J. I., \& Nagayama, R. S. (2007). The uncanny valley: Effect of realism on the impression of artificial human faces. Presence, 16(4), 337-351.

Seo, S. H., Geiskkovitch, D., Nakane, M., King, C., \& Young, J. E. (2015). Poor thing! Would you feel sorry for a simulated robot?: A comparison of empathy toward a physical and a simulated robot. ACM/IEEE International Conference on Human-Robot Interaction, 2015-March (pp. 125-132). https://doi.org/10.1145/26964 54.2696471

Shaw-Garlock, G. (2009). Looking forward to sociable robots. International Journal of Social Robotics, 1(3), 249-260.

Shaw-Garlock, G. (2011). Loving machines: Theorizing human and sociable-technology interaction. In M. H. Lamers \& F. J. Verbeek (Eds.), Human-robot personal relationships. HRPR 2010. Lecture Notes of the Institute for Computer Sciences, Social Informatics and Telecommunications Engineering (Vol. 59, pp. 1-10). Springer.

Simmel, G. (1892). Die Probleme der Geschichtphilosophie, 2nd ediz, 1905. Duncker \& Humblot.

Sparrow, R., \& Sparrow, L. (2006). In the hands of machines? The future of aged care. Minds and Machines, 16(2), 141-161.

Suzuki, Y., Galli, L., Ikeda, A., Itakura, S., \& Kitazaki, M. (2015). Measuring empathy for human and robot hand pain using electroencephalography. Scientific Reports, 5, 1-9. https://doi.org/10. 1038/srep15924

Stueber, K. (2017). Empathy. In E. N. Zalta (Ed.), The Stanford Encyclopedia of Philosophy (Spring 201).Metaphysics Research Lab, Stanford University.

Taylor, N., \& Signal, T. D. (2005). Empathy and attitudes to animals. Anthrozoös, 18(1), 18-27. https://doi.org/10.2752/0892793057 85594342 
Tam, K.-P. (2013). Dispositional empathy with nature. Journal of Environmental Psychology, 35, 92-104.

Tan, X. Z., Vázquez, M., Carter, E. J., Morales, C. G., \& Steinfeld, A. (2018, February). Inducing bystander interventions during robot abuse with social mechanisms. In Proceedings of the 2018 ACM/ IEEE international conference on human-robot interaction (pp. 169-177).

Titchener, E. (1909). Elementary psychology of the thought processes. Macmillan.

Titchner, E. (1924). A textbook of psychology. Macmillan.

Tomasello, M. (2014). The ultra social animal. European Journal of Social Psychology, 44(3), 187-194.

Turkle, S. (2010). In good company?: On the threshold of robotic companions. In Y. Wilks (Ed.), Close engagements with artificial companions (pp. 3-10). John Benjamins.
Wispe, L. (1986). The distinction between sympathy and empathy: To call forth a concept, a word is needed. Journal of Personality and Social Psychology, 50(2), 314-321. https://doi.org/10.1037/ 0022-3514.50.2.314

Young, A., Khalil, K. A., \& Wharton, J. (2018). Empathy for animals: A review of the existing literature. Curator: The Museum Journal, 61(2), 327-343.

Publisher's Note Springer Nature remains neutral with regard to jurisdictional claims in published maps and institutional affiliations. 